\title{
Optimization of two steps pretreatment techniques on lignin elimination in wheat straw to improve the bio-oil quality
}

\section{A.K. Verma, Shobhit Lakhera, Khan Chand, Ashutosh Dubey and T.K. Bhattacharya}

See end of the Paper for authors' affiliation Correspondence to :

A.K. Verma

Department of Biochemistry, College of Basic Sciences and Humanities, G.B. Pant University of Agriculture and Technology, Pantnagar (Uttarakhand) India Email: akv72@rediffmail.com
- ABSTRACT : Cross-linking of degraded lignin components present to bio-oil increases the density and causes instability during storage. Bio-oil quality and quantity from wheat straw was improved by alkaline and enzymatic treatment before pyrolysis. Alkaline pretreatment reduced the lignin content from 18 per cent to 10 per cent. Enzymatic pretreatment using $\beta$-glucosidase and cellulase in ratio 5:10, 10:10, 15:10 U for 24, 48, $72 \mathrm{~h}$ was optimized by using Response Surface Methodology (RSM) and eliminated 3.1 per cent lignin. The maximum reducing sugar and glucose content was found $24.2 \mathrm{~g} / \mathrm{L}$ and $15.488 \mathrm{~g} / \mathrm{L}$, respectively. Bio-oil yield by fast pyrolysis of treated and untreated wheat straw was 30 per cent and 27 per cent, respectively. Bio-oil of the treated wheat straw exhibited increased in $\mathrm{pH}$, higher density and decreased in viscosity. The flash point of bio-oil from treated wheat straw was very close to commercial diesel. Bio-oil was characterized by FTIR and GC-MS analysis.

- KEY WORDS : Bio-oil, Alkali pretreatment, Enzymatic pretreatment, Wheat straw, Lignin reduction, Pyrolysis, FTIR of bio-oil, GC-MS of bio-oil

- HOW TO CITE THIS PAPER : Verma, A.K., Lakhera, Shobhit, Chand, Khan, Dubey, Ashutosh and Bhattacharya, T.K. (2020). Optimization of two steps pretreatment techniques on lignin elimination in wheat straw to improve the bio-oil quality. Internat. J. Agric. Engg., 13(2) : 195-211, DOI: 10.15740/HAS/IJAE/13.2/195-211. Copyright@2020: Hind Agri-Horticultural Society. 